\title{
Design of bridge blasting demolition
}

\author{
Stefan Jangl ${ }^{1, *}$, Vladimir Kavicky and Michal Pilat ${ }^{2}$ \\ ${ }^{1}$ University of Zilina, Faculty of Security Engineering, Univerzitna 8215/1, 01026 Zilina, Slovakia \\ ${ }^{2}$ STV Group, Hvězdova 1716/2b, 14078 Praha-Nusle, Czech Republic
}

\begin{abstract}
The paper presents the design of bridge blasting demolition scheme. The blasting methods has become the preferred method for bridge demolition not only in war period but also where bridge service life is exceeded. Compared with the other demolition method, blasting evince more advantages as higher demolishing progress, lower cost and easier construction safety control. The design of bridge blasting demolition scheme contents blasting position, blasting parameters and safety protections.
\end{abstract}

\section{Introduction}

The bridges, as another engineering structures or buildings, are consensually demolished when is required. Aimed demolition is common mainly during the war period. During the period of peace, generally, they are demolished when the service life of bridge is exceeded [1]. This condition has various reasons. In major cases is caused by extreme weather conditions [2, 3] as floods, landslides (see Fig. 1) or causes by exceeded mechanical loading or fatigue, for example Genova bridge in Italy (see Fig.2). In this cases whole structure or parts have to be demolished. Generally for bridge demolition three fundamental methods can be used: (i) Mechanical demolition, using specialized mechanical equipment and tools (hydraulic excavators, skid steers loaders and demolition robots), (ii) Crane and Wrecking Ball, one of the earliest methods of demolition, and (iii) Using explosions. Compared with blasting demolition methods, other bridge demolition methods requires more manual mechanical cutting, crushing, lifting and the demolishing progress is relatively slow with higher cost and the construction safety is difficult to control [1].

The demolition of structures using explosive presents most rapid, safe and efficient way, but requires planned blast design parameters with respect to geometric and strength properties of the structure to be demolished. Mandal in [4] presents successful demolition of three old bridge piers by different blast designs.

\footnotetext{
*Corresponding author: stefan.jangl@fbi.uniza.sk
} 

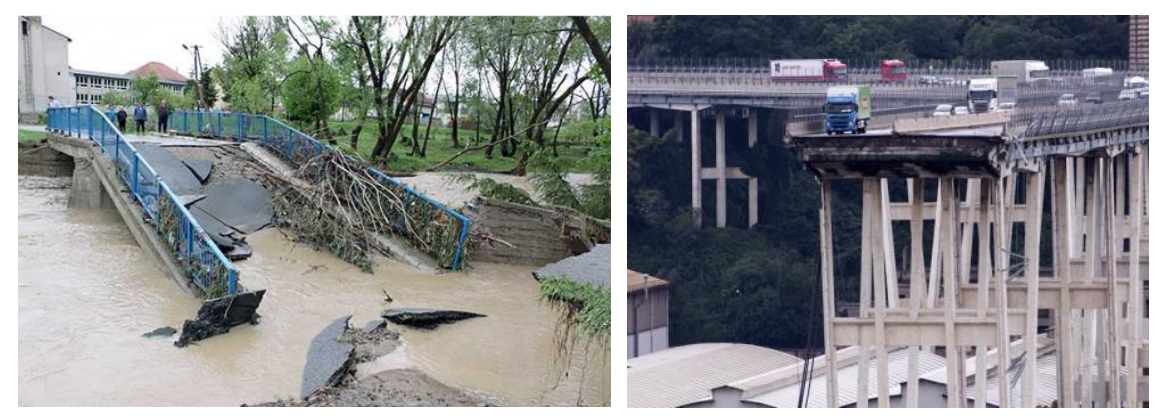

Fig. 1. Damaged bridges caused by a) extreme weather condition b) exceeding the service life

For the rewarding demolition of structural part using explosives various phenomena have to be described and known: blast wave propagation $[6,7,8]$, blasting parameters as well as behaviour [9, 10,], resistance of blast loaded structures [11 -14], even the resistance of electrical cables used for demolition [15]. For the blast demolition various explosive charges can be used $[16,17]$.

\section{Bridge blast demolition}

The purposeful destruction of the bridge supports is focused mainly on the intermediate supports, as they prevented the extension of the temporary bridges. These supports are mainly built from reinforced concrete. The highway intermediate supports have strong reinforcement and are built with permanent destruction equipment. Intermediate supports without a permanent destruction device are destroyed with two or more concentrated charges, as is described in the second part of this paper. The charges are stored in charge branches or in alcoves of the same height. If there was no other solution, loosely attached concentrated charges can be used. The distance between the charges should not be greater than two radii of $2 \mathrm{r}$ efficiency and the distance from the support head must be one radius of efficiency $r$. The radius of effectiveness $r$ of the charge was determined as the largest line of resistance that the charge explosion must overcome.

\subsection{Description of the demolished bridge}

After the crisis situation, it was necessary to perform a diagnostics of the supporting structure. The survey was carried out by a professionally qualified person for the assessment of the statics of civil engineering. From the preliminary survey it was clear that the crucial loadbearing structural elements are significantly disturbed and the overall stability and durability of the structure is insufficient and unsuitable for further operation. The bridge support cannot be used for the construction of a temporary bridge structure and therefore it was necessary to rehabilitate it. For the rehabilitation of the building structure, it was necessary to prepare a detailed survey. Based on the survey, a competent person issued an opinion that the building must be rehabilitated. The location of the building structure in question significantly limits the remediation by means of machine mechanisms. The location of the pillar in the riverbed and its foundation under the terrain, the incoherent terrain of the river banks has a significant impact on the safe position of the mechanisms. Based on an assessment of the existing condition, the fastest and safest way to remove a pillar of a bridge structure is destructive 
work through an explosive. Other parts of the bridge structure located outside the river bed will be removed by machinery means

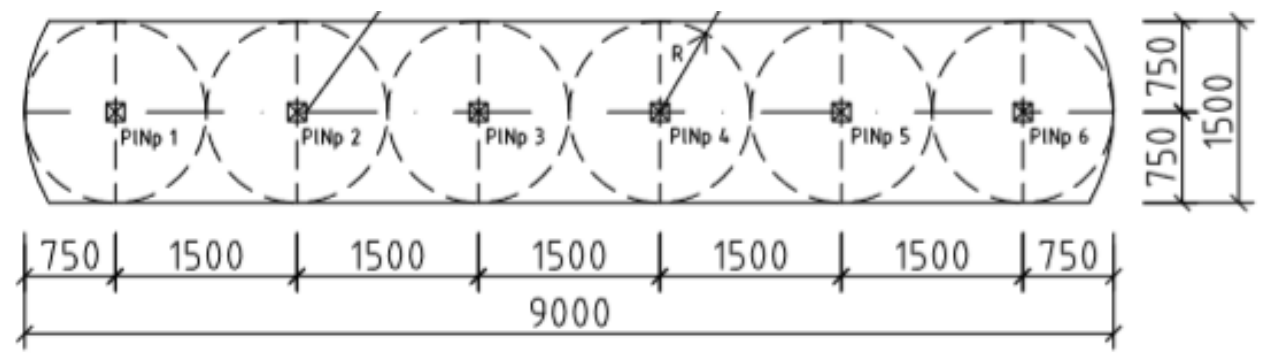

Fig. 2. Dimensions of bridge pillar and the placement of explosive charges.

After the collapse of road bridge after the persistent rain causes flooding, the internal pillar must the demolished. The concrete pillar dimensions are: width $9000 \mathrm{~m}$, depth $1500 \mathrm{~mm}$.

\subsection{Bridge blasting demolition scheme}

In the blasting demolition of reinforced concrete bridges blasting parameters have to be set. Presented demolition scheme is design according to the methodology described in [18]. Blasting parameters ( $N$ charge weight $[\mathrm{kg}], A$ demolished material factor, $B$ explosion position factor and $R$ efficiency radius $[\mathrm{m}]$ ) for each explosive charge positions (see Fig. 3) were set. Structural response and resistance on such dynamic loading depend on the construction materials $[19,20]$.

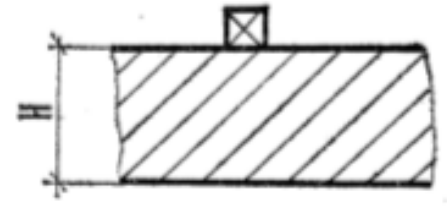

(a) freely paleced charge

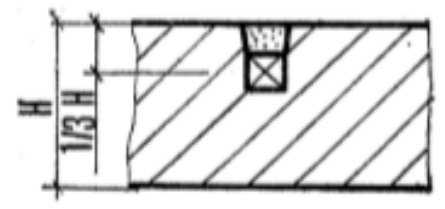

(c) closed charge in $1 / 3$ of thickness

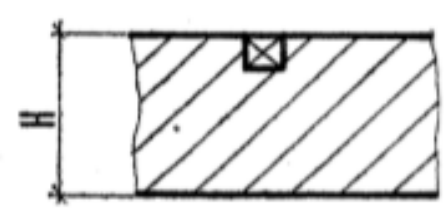

(b) embbeded charge

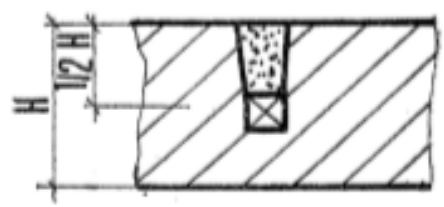

(d) closed charge in the middle of thickness

Fig. 3. Explosives charges positions.

Figure 4 compare the required weight for each type of explosive charge. It is clear, that the minimum demand on explosion and the cheapest way to remove a bridge pillar is a closed charge in the middle of the structure. Six concentrated charges are needed to be placed in pillar section. The distance between the charges will be 1.5 meters (see Fig.5). 


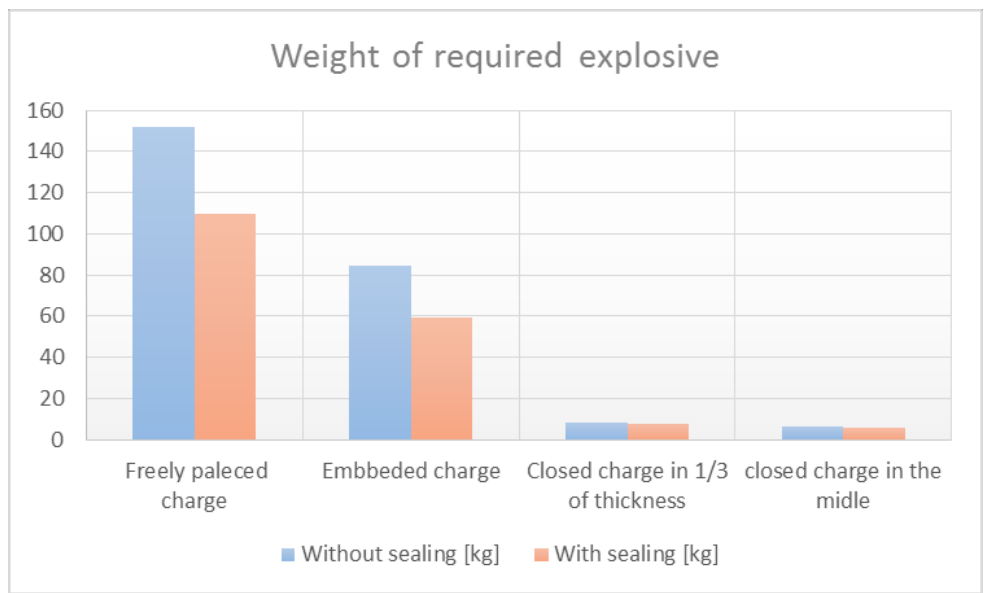

Fig. 4. Comparison of required weight of explosives.

Because of presence of a permanent device for the destruction, it will not be necessary to build boreholes to place the charges. Plastic explosive Pl Np 10 (explosive based on a nonexplosive plasticizer with active substance pentrite) will be used for detonation. Traditional explosives TNT for the charge [21]. Both belongs to explosives with higher efficiency, in the table 1 there are listed the main explosive characteristics of considered explosives. It is completely safe with the handing, it is not sensitive to punch friction and impact. It can be shaped according to the required form. It is detonated by a detonator or detonation cord. As is obvious that for the design traditional high efficiency explosives were considered. It is possible to use so called ANFO explosives (ammonium nitrate and fuel oil explosives), but considering difference efficacy following from their diverse explosive characteristics. Comparison of the efficacy of ANFO explosives and TNT explosives is described [22].

Table 1. Explosives characteristics.

\begin{tabular}{|c|c|c|c|c|}
\hline Explosive & $\begin{array}{c}\text { Explosive } \\
\text { velocity }[\mathrm{m} / \mathrm{s}]\end{array}$ & $\begin{array}{c}\text { Heat of } \\
\text { combustion } \\
{[\mathrm{kJ} / \mathrm{kg}]}\end{array}$ & $\begin{array}{c}\text { Density } \\
{\left[\mathrm{g} / \mathrm{cm}^{3}\right]}\end{array}$ & $\begin{array}{c}\text { Explosive } \\
\text { pressure } \\
{[\mathrm{GPa}]}\end{array}$ \\
\hline TNT & 6800 & 4200 & 1.58 & 18.4 \\
\hline P1 Np 10 & 7600 & 4982 & 1.45 & 21.7 \\
\hline
\end{tabular}

The design of blasting network of presented bridge consider the initiation of one detonator for each hole. All electric detonators are connected into a series initiation network. A combined ignition will be used for the detonation of individual charges, electric ignition together with the fire ignition. A detonator of the Že-B type and an RKA 4J detonator are designed. The voltage to the detonators is brought with a single-core CYL 1 cable. 


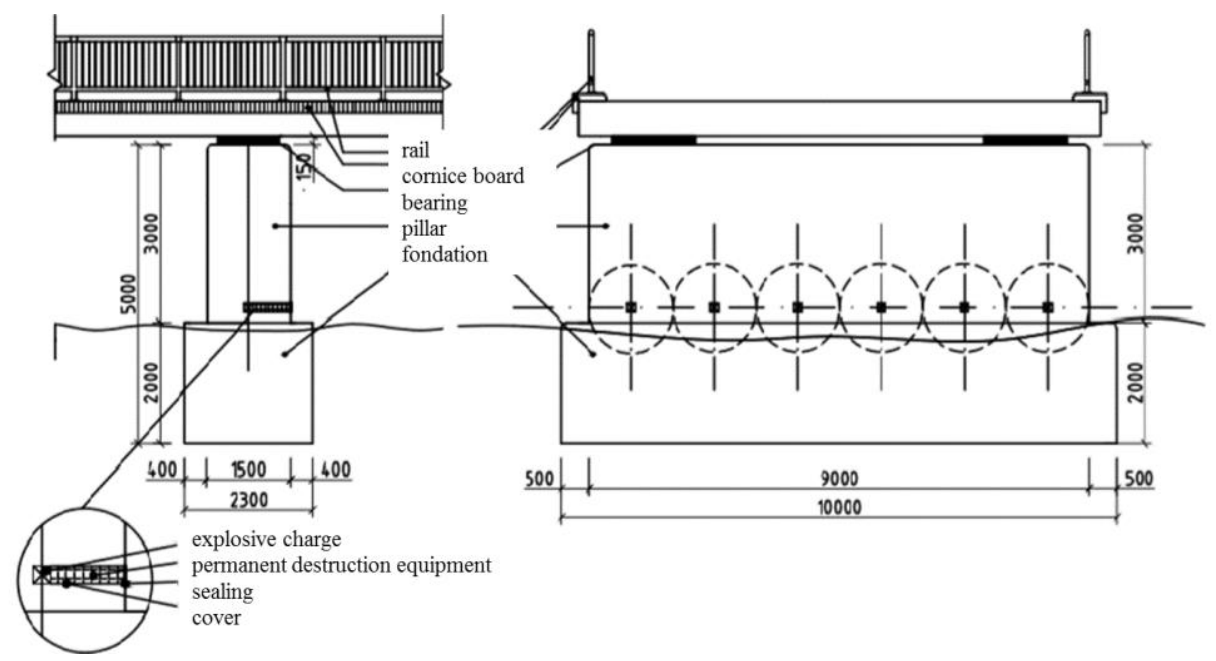

Fig. 5. Blasting network.

It is necessary to design correctly the explosive charge dimensions and placement. Due to high dust content, the structure is usually moistened with water before blasting (the loadbearing capacity of load-bearing structures due to the increased weight of the wet structure has to be verified). The safety protection design has to be carried out. During the blasting, the dynamic condition of the surrounding structures $[23,24]$ must also be assessed in advance to verify that they are not affected by the created pressure wave. The second aspect are blasting flying debris. Surrounding buildings can to be protected using some methods mentioned in [26, 27]. Detailed methods of safety protection design is reported in [1].

Destroying bridge, an electrical ignition network is set up to detonate the calculated charges. It is advantageous to use a double electric mains network. The network must be transparent and easy to check and repair. Setting up the electrical ignition network, safety precautions must be observed and budgets for the ignition network must be made and care must be taken to ensure that the calculated resistance of the serial network does not exceed the permissible maximum ignition resistance for the used igniter and that the calculated ignition pulse is greater than at least.

The maximum resistance of series networks (Rmez) depends on the energy that the fuse can supply to the network and on the ignition pulse of detonators or igniters, where $\mathrm{N}$ is energy of igniter and $\mathrm{Ez}$ is an impulse of used detonators in $\mathrm{J} / \Omega$

$$
R_{m e z}=\frac{N}{E_{z}}
$$

In the case of serial ignition networks, when the network is not branched, the current flowing through the ignition network is equal to the current through each detonator. The time in all detonators is the same, and thus the ignition pulse delivered to each detonator is the same. Therefore, the total resistance of the ignition network is calculated

$$
R_{n}=R_{i}+R_{s}+m \cdot R_{d}
$$


where

$R_{n}$ is resistance of all network in $\Omega, R_{i}$ is resistance of inlet line in $\Omega$,

$R_{s}$ is resistance of section line $\Omega, m$ is number of electrical detonators in network and $R_{d}$ is resistance of one detonator.

Is required to assess the appropriateness of fuse comparing of allowable maximal resistance

$\mathrm{R}_{\text {mez }}$ with the absolute network resistance $\mathrm{R}_{\mathrm{n}}$. If the network has to be functional the

condition has to be fulfilled:

$$
R_{n} \leq R_{m e z}
$$

\section{Conclusions}

The fastest and most effective removal of a bridge structure after an undesirable event is the removal by blasting. As is obvious from different presented methods, the cheapest way is to locate the explosive in a closed charge in the middle of the demolished structure (in the charge branch). For this type, $5.75 \mathrm{~kg}$ of TNT explosives is required for the section length of $1.5 \mathrm{~m}$. The demolition using blast can be used for purposeful demolition from various reasons.

\section{References}

1. D. Mao et al., IOP Conf. Ser.: Earth Environ. Sci. 567012022 (2020)

2. B. Leitner, M. Luskova. Transport Means - Proceedings of the International Conference, pp. 569-573 (2018)

3. M. Luskova, Z. Dvorak, B. Leitner. Transport Means - Proceedings of the International Conference, pp. 306-309 (2015)

4. S.K. Mandal, M.M. Singh, R.B. Singh, Proceedings of the twenty-seventh annual conference on explosives and blasting technique, I pp. 215-233 (2001)

5. C. Xie, J. Yang. Advanced Materials Research Volume: 255-260 Pages: 17061710 Part: 1-6 Published: 2011

6. L. Figuli, D. Cekerevac, C. Bedon, B. Leitner. Advances in Civil Engineering, 2020, 8871412, (2020)

7. Z. Zvakova, L. Figuli, V. Kavicky, et al. Transport Means - Proceedings of the International Conference, pp. 1100-1104 (2016)

8. M. Ivančo, Erdélyiová, R., Figuli, Transportation Research Procedia, 40, pp. 13561363 (2019)

9. L. Figuli, et al, IOP Conf. Ser. Earth Environ. Sci. 44 (2016)

10. L. Figuli, Z. Zvaková, C. Bedon, Procedia Eng. 192 (2017)

11. L. Figuli, C. Bedon, Z. Zvaková et al. Procedia Eng. 199, pp. 2463-2469 (2017)

12. L. Figuli, D. Papan, Applied Mechanics and Materials, 617 (2014)

13. M. Ivančo, J. Trajkowski, L. Figuli, R. Erdelyiova. MATEC Web of Conference 313, 00026 (2020)

14. C. Bedon, L. Figuli, Transport Means - Proceedings of the International Conference, pp. 977-984, (2017)

15. Z. Nyikes, T.A. Kovács, NATO Science for Peace and Security Series C: Environmental Security, pp. 291-296 (2020)

16. L.Figuli, L.; Erdelyiova, R.; Papan, D. et al., Matec web of conferences, 313 (2020)

17. D. Papán, Z. Papánová. MATEC Web of Conference 313, 00019 (2020)

18. Explosions and demolition. Žen $2 / 6$ s, Prague, Czech republic (1982)

19. Z. Hejmal, P. Manas, J. Stoller, Proceedings of the 20th international scientific conference transport means, pp. 881-884 (2016)

20. D. Papán, Z. Papánová, MATEC Web of Conferences 196, 01037 (2018) 
21. V. Kavicky, L. Figuli, S. Jangl, Z. Ligasová, WIT Transactions on The Built Environment, 141 (WIT Press 2014)

22. L. Figuli, V. Kavicky, S. Jangl, Z. Zvakova, Communications - Scientific Letters of the University of Zilina, 20 (2), pp. 23-27 (2018)

23. D. Papán, Z. Papánová, MATEC Web of Conferences 251, 04057 (2018)

24. D. Papán, Z. Papánová, Procedia Eng. 91 (2014).

25. D. Papán, Z. Papánová, MATEC Web of Conferences 313, 00019 (2020) 